\title{
Airplane noise and the taste of umami
}

\author{
Charles Spence $^{1 *}$, Charles Michel ${ }^{1}$ and Barry Smith ${ }^{2}$
}

\begin{abstract}
Have you ever noticed how many people ask for a Bloody Mary or tomato juice from the drinks trolley on airplanes? The air stewards have, and when you ask the people who order, they will tell you that they rarely order such a drink at any other time. Could it be that umami-rich tomato provides one of the only basic tastes that is relatively unaffected by the loud background noise that one is exposed to while in flight? That is the research suggestion, or hypothesis, outlined in this opinion piece. Should such a claim be validated by future research, the potential application for airline catering could be huge.
\end{abstract}

\section{Introduction}

"A loud noise, for instance, may prevent entirely our ability to smell or taste, yet softly played dinner music can create an environment favourable for elegant dining." ([1] p. 7).

Researchers have long suspected that loud noise might interfere with an individual's ability to taste the flavour of food [1]. Nevertheless, the earliest experimental findings on the topic failed to demonstrate any such crossmodal effect [2]. However, more recent research has now clearly demonstrated that loud noise can suppress the perception of certain basic tastes [3]. Specifically, woods and his colleagues had their participants eat a range of savoury and sweet snacks (including potato chips, cheese, biscuits, and flapjack) while listening to loud white noise presented over headphones [3]. Their results revealed that the perception of sweetness and saltiness were significantly reduced by the presence of loud white noise (Figure 1).

Considering that the sound inside of an airborne airplane is not too dissimilar in terms of either its loudness or unpleasantness to the white noise used in Woods et al.'s [3] study (the interior of an Airbus A320 is said to run at $86 \mathrm{~dB}$, http://ask.metafilter.com/37070/Howloud-is-the-inside-of-an-airplane; while the normal level

\footnotetext{
* Correspondence: charles.spence@psy.ox.ac.uk

${ }^{1}$ Crossmodal Research Laboratory, Department of Psychology, Oxford University, Oxford, UK

Full list of author information is available at the end of the article
}

for commercial planes in flight is $80-85 \mathrm{~dB}$, [4]; although the sound intensity likely varies somewhat depending on the type of aircraft and how close to the engines passengers happen to be seated), it does not seem unreasonable to suggest that the perception of sweetness and saltiness of foods and drinks served in the air would also be suppressed. Unfortunately, however, the authors failed to assess whether any of the other basic tastes (e.g., sourness, bitterness, or the savouriness of umami; $[5,6])^{a}$ would be similarly suppressed by the presence of loud background noise. The intuition is, surely, that all tastes would be affected equally.

Not all basic tastes behave similarly though; when it comes to the suppression of tastes, for instance, combining sweet, sour, salty, and bitter tends to lead to an overall suppression of taste. Umami, however, is immune to this effect. There is even some evidence to suggest that it fails to show the suppression effect and may actually boost some of the other basic tastes [7]. So all tastes may not be created equal when it comes to crossmodal noise-induced sensory suppression effects. The hypothesis that background noise might not impact on the perception of umami is supported by the results of some of the earliest research to have studied the impact of sound on taste/flavour perception [2]. It would also be consistent with anecdotal reports from those who test airline food for some of the world's biggest airlines [8]. In her early research, Pettit reported that a variety of different types of background noise failed to impact on people's ratings of tomato juice samples in a central test location study. The irony here is that should Pettit have chosen to test another foodstuff then different results may well have been obtained, and the field of sound/music-taste/ 


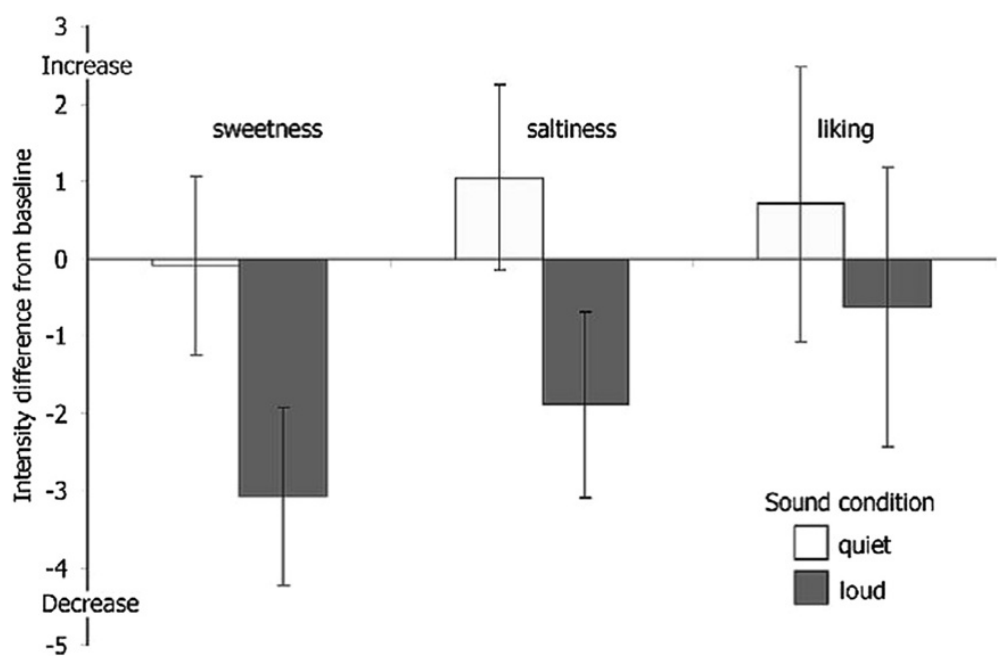

Figure 1 The effect of quiet (45-55 dB) and loud (75-85 dB) background noise on rated sweetness, saltiness, and liking in Woods et al.'s study, relative to the silent baseline condition (Experiment 1). Note that a negative value indicates a lower level than baseline and a positive value a higher level. Error bars = 2 SEM. (Figure reprinted from Woods et al. [3]).

flavour interaction research may not have been held up for quite as long as it was (see [9], for a review).

This is, in fact, where the anecdotal observation outlined at the start of this piece comes into play. Should the reported shift in passengers' preference toward ordering tomato-based beverages during flights turn out to be an accurate representation of the true state of affairs, what explains this desire for tomato-based foods? A key feature of tomatoes is that they are rich in umami [10]. So the question arises as to whether umami might be the one basic taste whose perception is relatively unaffected by the level of background noise. Should it turn out that the taste of umami really is resistant to loud noise, then that will certainly bode well for the umami-based menu recently introduced by British Airways [11]. Indeed, more generally, there would appear to be something of a growing interest amongst western chefs in the use of umami-rich ingredients in cuisine [12], though note that many umami-rich ingredients have been used in Italian cuisine for a long time; think only of the classic 'pasta al pomodoro', often drowned under large amounts of parmesan cheese and tomato sauce; not to mention tomato and anchovy sauces in pizza recipes, all umami-rich. The last combination producing synergistic umami where the umami hit is presumably boosted.

\section{"The inexplicable blandness of airline food has been pondered at 30,000 feet by generations of travellers." ([13], p. 13).}

Of course, anything we can do to gain a better understanding about why most food tastes less than wonderful in the plane has to be welcome (see [14] for some of the earliest research on this topic). Indeed, some carriers, such as Lufthansa and Singapore Airlines, have even built specialized testing facilities in order to mimic the conditions of the average passenger without anyone having to leave the ground [8], all with the aim of making their food taste better in the air.

Understanding (or predicting) how flavour perception might be affected by a noise-induced reduction in the perception of any basic taste in airline food (or for that matter in any other food) is by no means a simple matter. First, as has already been noted, the basic tastes interact, and mutually suppress one another in ways that are sometimes unpredictable, e.g., [7,15-17], with umami being suppressed when combined with any of the other basic tastes, while at the same time enhancing sweetness and saltiness perception. Second, the reduction in the contribution of volatile compounds to flavour perception given the low cabin pressure, not to mention the dry air [8], will also likely reduce any smell-induced taste perception (e.g., as in the case of olfactory-induced sweetness or bitterness; [18]). Note here also that Maga and Lorenz [19] reported that their participants were significantly less sensitive to the four basic tastes in an environment designed to simulate what it is like at $5,000 \mathrm{ft}$ above sea level than at sea level. Finally, it should be noted that a growing body of research now shows that background sound can also affect olfactory perception [20-22].

Should it be proved that the perception of umami is indeed noise-insensitive, then one might also want to recommend an umami-rich menu - that is, foods such as parmesan cheese, tomatoes, and mushrooms - to all those vocal restaurant critics out there, especially it seems in North America, who have been complaining that the background noise in many restaurants is simply too loud 
nowadays so that they can no longer taste/enjoy their food [23-25]. In fact, Sietsema [24,25] measured some restaurants at $90 \mathrm{~dB}$ at especially busy times, that is, higher than the noise levels used in the study by Woods et al. [3], and higher too than the noise levels experienced by passengers in commercial planes while in flight (Figure 2) [4]!

We would, of course, still be left with the question of what exactly it is that is so special about umami relative to the other 'basic' tastes. But here it is worth remembering that the different tastes serve different evolutionary functions, and what is more we would not be the first to suggest that loud noise might not affect all tastes equally [26]. Furthermore, the latest research from Obrist et al. [27] has demonstrated that umami appears to be special amongst the five basic tastes in being rated as the most intense, and even after matching for intensity effects, gives rise to a sensation that lingers for longer than any of the other tastes (Figure 3). This representation of taste experiences would support the idea that monosodium glutamate, when combined with other tastes, has the power to enhance them [7] or maybe even 'lift up' overall taste experiences, in particular with loud ambient noise.

Perhaps neuroimaging, especially MRI where the loud background noise is thrown in for free [28], might be able to help discern where exactly in the human brain such curious crossmodal interactions are taking place.

As a first step at the behavioural level, the ideal solution here might well be to serve the same selection of foods (either umami-rich or without umami) to participants in four different conditions: i) While in flight (i.e., with loud background noise and with low cabin air pressure); ii) While in flight but wearing noise-cancelling headphones (low background noise and low air pressure); iii) On the ground with the engines running, or perhaps, more likely, with prerecorded engine sounds being played back to participants (loud background noise and normal air pressure); and iv) On the ground with the engines off (low background noise and normal air pressure). One would presumably want to assess taste and flavour intensity ratings as well as participants' hedonic responses to the foods served. We would certainly welcome the results of such a study.

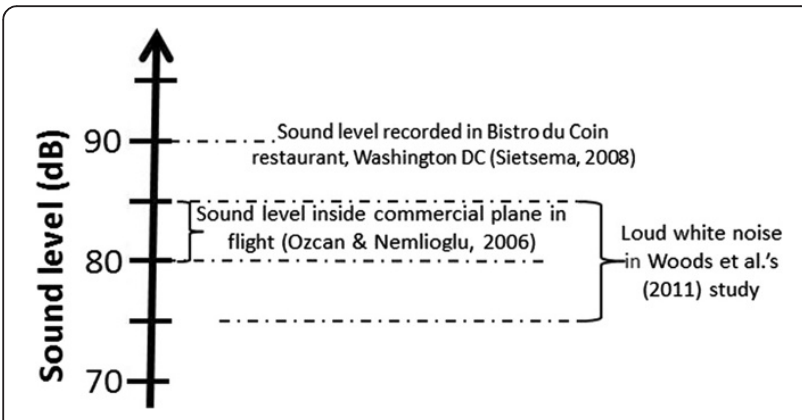

Figure 2 Sound levels in a variety of eating environments.

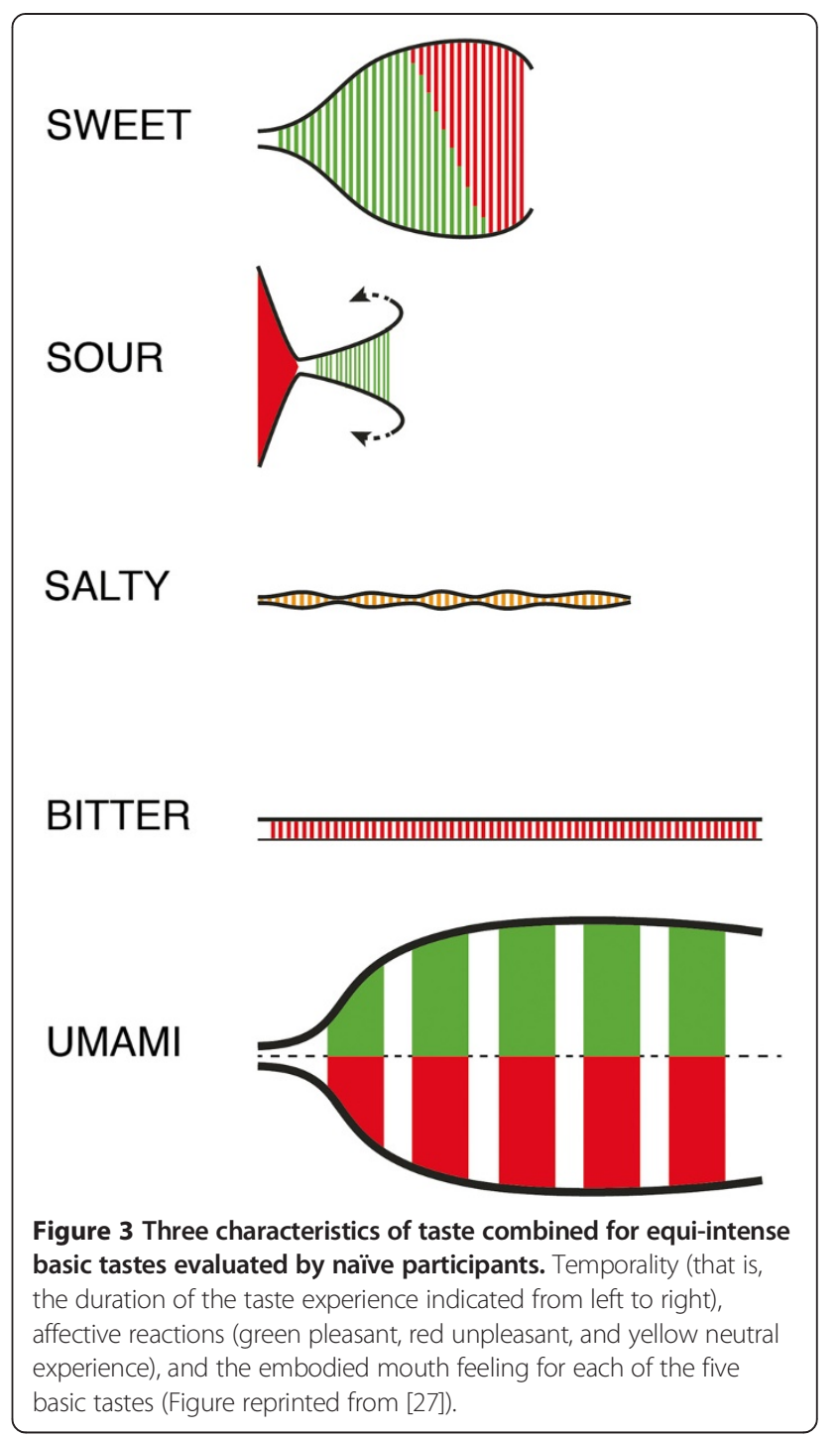

\section{Conclusions}

In conclusion, perhaps all those travellers who order a Bloody Mary after the seatbelt sign has been turned off have figured out intuitively what scientists are only now slowly coming to recognize empirically, regarding the interaction between what we hear and what we taste $[9,11]$. Only future research will be able to definitively show whether certain tastes are more or less affected by background noise (or music) than others. Answering this question may have implications for all of us who need, on occasion, to eat and/or drink in the sky!

\section{Endnote}

${ }^{\text {a}}$ Though, note that it is something of an open question as to how many 'basic' tastes there actually are [29], and whether they should even be called basic in the first place $[30,31])$. 


\section{Competing interests}

The authors declare that they have no competing interests.

\section{Authors' contributions}

The three authors CS, CM, \& BS all contributed to the writing of this manuscript. All authors read and approved the final manuscript.

\section{Authors' information}

Charles Michel is the first chef in residence at the Crossmodal Research Laboratory.

\section{Acknowledgements}

The authors wish to thank Heston Blumenthal and Lisa Methven for helpful discussion on the impact of sound on umami and flavour perception. The authors received no funding for this piece of work.

\section{Author details}

${ }^{1}$ Crossmodal Research Laboratory, Department of Psychology, Oxford University, Oxford, UK. ${ }^{2}$ Centre for the Study of the Senses, School of Advanced Studies, University of London, London, UK.

Received: 31 December 2013 Accepted: 22 January 2014 Published: 20 February 2014

\section{References}

1. Crocker EC: The technology of flavors and odors. Confectioner 1950, 34:7-10.

2. Pettit $L A$ : The influence of test location and accompanying sound in flavor preference testing of tomato juice. Food Technol 1958, 12:55-57.

3. Woods AT, Poliakoff E, Lloyd DM, Kuenzel J, Hodson R, Gonda H, Batchelor J, Dijksterhuis GB, Thomas A: Effect of background noise on food perception. Food Qual Preference 2011, 22:42-47.

4. Ozcan HK, Nemlioglu S: In-cabin noise levels during commercial aircraft flights. Can Acoust 2006, 34:31-35.

5. Kawamura Y, Kare MR: Umami: A Basic Taste - Physiology, Biochemistry, Nutrition, Food Science. New York, NY: Marcel Dekker; 1987.

6. Yasuo T, Kusuhara Y, Yasumatsu K, Ninomiya Y: Multiple receptor systems for glutamate detection in the taste organ. Biol Pharmacol Bull 2006, 31:1833-1837

7. Suwankanit C, Dermiki M, Kennedy OB, Methven L: Umami: Suppressed by all Other Tastes but Itself an Enhancer of Salty and Sweet Perception. Rio de Janeiro, Brazil: Poster presented at 10th Pangborn Sensory Science Symposium; 2013.

8. Michaels D: Test flight: Lufthansa searches for savor in the sky. Wall Street J 2010. [http://online.wsj.com/article/SB1000142405274870329490457538495 4227906006.html]

9. Spence C: Auditory contributions to flavour perception and feeding behaviour. Physiol Behav 2012, 107:505-515.

10. Oruna-Concha MJ, Methven L, Blumenthal H, Young C, Mottram DS: Differences in glutamic acid and 5'-ribonucleotide contents between flesh and pulp of tomatoes and the relationship with umami taste. J Agric Food Chem 2007, 55:5776-5780.

11. McCartney S: The secret to making airline food taste better. Wall Street J 2013. [http://live.wsj.com/video/the-secret-to-making-airline-food-tastebetter/8367EF44-52DD-41C4-AC4A-FFA6659F3422.html\#!8367EF44-52DD41C4-AC4A-FFA6659F3422]

12. Umami Information Center: Dialogue between Peruvian chefs and Monell Scientists. 2011. [http://www.umamiinfo.com/2011/08/dialogue-betweenperuvian-chefs-and-monell-scientists.php]

13. Connor S: Science finds the plane truth about in-flight meals. Independent; 2010 http://www.independent.co.uk/news/science/sciencefinds-the-plane-truth-about-inflight-meals-2107130.html.

14. Green DM, Butts JS: Factors affecting acceptability of meals served in the air. J Am Diet Assoc 1945, 21:415-419.

15. Breslin PAS, Beauchamp GK: Salt enhances flavor by suppressing bitterness. Nature 1997, 387:563.

16. Gillan DJ: Taste-taste, odor-odor, and taste-odor mixtures: greater suppression within than between modalities. Percept Psychophys 1983, 33:183-183.

17. Savant L, McDaniel MR: Suppression of sourness: a comparative study involving mixtures of organic acids and sugars. Percept Psychophys 2004, 66:642-650

18. Stevenson RJ, Boakes RA: Sweet and sour smells: learned synaesthesia between the senses of taste and smell. In The Handbook of Multisensory
Processing. Edited by Calvert GA, Spence C, Stein BE. Cambridge, MA: MIT Press; 2004:69-83.

19. Maga JA, Lorenz K: Effect of altitude on taste thresholds. Percept Mot Skills 1972, 34:667-670

20. Seo HS, Gudziol V, Hähner A, Hummel T: Background sound modulates the performance of odor discrimination task. Exp Brain Res 2011, 212:305-314.

21. Seo HS, Hähner A, Gudziol V, Scheibe M, Hummel T: Influence of background noise on the performance in the odor sensitivity task: effects of noise type and extraversion. Exp Brain Res 2011, 222:89-97.

22. Seo HS, Hummel T: Auditory-olfactory integration: congruent or pleasant sounds amplify odor pleasantness. Chem Senses 2010, 36:301-309.

23. McLaughlin K: Pass the salt ... and a megaphone. Wall Street J 2010. [http:// online.wsj.com/article/SB10001424052748704022804575041060813407740.html]

24. Sietsema T: No appetite for noise. The Washington Post. 2008. [http://www.washingtonpost.com/wp-dyn/content/article/2008/04/01/ AR2008040102210_pf.html]

25. Sietsema T: Revealing raucous restaurants. The Washington Post. 2008. [http://www.washingtonpost.com/wp-dyn/content/article/2008/04/04/ AR2008040402738.html?sid=ST2008040402725]

26. Ferber $C$, Cabanac M: Influence of noise on gustatory affective ratings and preference for sweet or salt. Appetite 1987, 8:229-235.

27. Obrist M, Comber R, Subramanian S, Piqueras-Fiszman B, Velasco C, Spence $C$ : Temporal, affective, and embodied characteristics of taste experiences: A framework for design. Full paper accepted for CHI 2014

28. de Araujo IET, Kringelbach ML, Rolls ET, Hobden P: Representation of umami taste in the human brain. J Neurophysiol 2003, 90:313-319.

29. Stuckey B: Taste What You're Missing: The Passionate Eater's Guide to Why Good Food Tastes Good. London: Free Press; 2012.

30. Delwiche J: Are there 'basic' tastes? Trends Food Sci Technol 1996, 7:411-415.

31. Erikson RP: A study of the science of taste: on the origins and influence of the core ideas. Behav Brain Sci 2008, 31:59-105.

doi:10.1186/2044-7248-3-2

Cite this article as: Spence et al:: Airplane noise and the taste of umami. Flavour 2014 3:2.

\section{Submit your next manuscript to BioMed Central and take full advantage of:}

- Convenient online submission

- Thorough peer review

- No space constraints or color figure charges

- Immediate publication on acceptance

- Inclusion in PubMed, CAS, Scopus and Google Scholar

- Research which is freely available for redistribution

Submit your manuscript at www.biomedcentral.com/submit
C BioMed Central 